\title{
Síndrome de Li-Fraumeni asociado a carcinoma papilar de tiroides
}

\author{
- Juanita Martínez, Einstein Viana, Jorge Rugeles, Manuel González, Estephannia Mora
}

IMAT Oncomédica (Montería)

Introducción: el síndrome de Li-Fraumeni se caracteriza por la aparición de tumores en múltiples órganos, generalmente a temprana edad; es causado por mutaciones germinales en el gen TP53, que codifica el gen supresor tumoral p53.

Materiales y métodos: se presenta el caso de una paciente femenina de 22 años, quien debutó con carcinoma papilar de tiroides, encontrando múltiples antecedentes oncológicos en línea materna en el árbol genealógico de cuatro generaciones: carcinoma de mama, gástrica, SNC, ovario, tiroides, páncreas, sarcomas, leucemia, muchos de ellos diagnosticados y fallecidos en edades tempranas.

Resultados: después de una asesoría genética, se ordenó hacer la secuenciación completa y el análisis de duplicaciones y deleciones en el gen TP53. El estudio molecular en una muestra de ADN proveniente de saliva reveló la mutación patogénica en el gen TP53 c.518T>C (p.Va1173A1a), que confiere el síndrome de Li-Fraumeni, por lo que se realizaron estudios imaginológicos sin evidencia de enfermedad oncológica concomitante.

Conclusiones: en Colombia son pocos los casos confirmados molecularmente de síndrome de Li-Fraumeni. Los portadores presentan predisposición a desarrollar cáncer a edades tempranas, entre los que destacan sarcomas, cáncer de mama, leucemias, linfomas y tumores cerebrales; aunque se puede generar cualquier tipo de tumor, existen pocos casos documentados de cáncer papilar de tiroides (CPT) en el contexto de LF. El diagnóstico y manejo del síndrome de Li-Fraumeni debe estar a cargo de un equipo multidisciplinario y contar con asesoría genética para el paciente y sus familiares. 